\title{
Lights, Camera, Action! Increasing First-Year Engineering Student Aca- demic Performance via an Innovative Pre-Orientation Program
}

\section{Dr. Karen T. Marosi, Bucknell University}

Dr. Karen T. Marosi is an Associate Dean of Engineering at Bucknell University. She holds a Ph.D. in Civil Engineering from The Pennsylvania State University. As Associate Dean, she has worked to enhance the academic success of students in the College of Engineering especially those who come from under-represented groups in engineering.

\section{Ms. Barbra Steinhurst, Bucknell University}

Barbra Steinhurst is the Director of the Engineering Success Alliance at Bucknell University. She has extensive experience working with students on a variety of diversity spectra. Her previous roles have included teaching college mathematics and connecting rural students to accessible educational opportunities. 


\title{
Lights, Camera, Action! Increasing First-Year Engineering Student Academic Performance via an Innovative Pre-Orientation Program
}

\begin{abstract}
An intensive, week-long, residential pre-orientation program was developed to improve the firstsemester academic performance of students in the Engineering Success Alliance (ESA) Program at Bucknell University. Historically, in the entry level physics and calculus courses taken by all engineering majors in the first semester, students in the ESA would struggle to earn passing grades on the first set of exams that commonly occur during the fourth week of classes. Since poor performance on the first exam jeopardizes future success in these courses, ESA staff recognized a need for a longer period of preparation focused primarily on skills and relationships that optimize academic performance. In the summer of 2012, a pre-orientation program named "Backstage Bucknell” was added to the ESA. Backstage Bucknell was themed around a theatrical production where the students were the "stars" of the show. Each part of the program was designed to support one or more of the goals of the ESA which are 1) building academic self efficacy, 2) creating a sense of community and belonging, 3) balancing academic, social life and self, and ultimately 4) retention. There was a significant increase in the scores on the first physics exam for the Backstage Bucknell ESA 2016 participants as compared to the previous ESA 2015 class. Given that the student selection process and other programming for the ESA students has been the same this academic year as in the past, it is likely that these increases in performance can be attributed to the Backstage Bucknell programming.
\end{abstract}

Background

The ESA is an academic success program that provides students from under-resourced high schools with the skills they need to be successful in the nationally recognized engineering program at Bucknell University. As observed by George Pierson, the President and CEO of Parsons Brinckerhoff and a 1984 graduate of the College of Engineering, "The United States is simply not graduating enough engineers, and students from under-resourced areas, including minorities, are under-represented in the profession. To remain competitive as a company and as a country, we must draw students of all backgrounds into engineering fields.” The National Research Council echoes these same thoughts in many recent publications including Rising Above the Gathering Storm ${ }^{1}$ and Rising Above the Gathering Storm, Revisited ${ }^{2}$. The College of Engineering has developed a partnership with this firm and several other industry partners to envision and implement a program that has the goal of serving as an innovative part of the national effort to increase diversity in the engineering workforce. 
The University and the College of Engineering are dedicated to extending the advantages of the educational program to talented young men and women regardless of financial need. Creating a more diverse student body is a high priority for the University. The University recruits students from diverse communities through a number of special programs that identify and recruit talented students often from urban and inner city areas. The College of Engineering is a highly selective and nationally recognized program. The acceptance rate for class of 2016 for the College of Engineering was 23\% and the average SAT score for the class of 2016 in Quantitative Reasoning was a 720. The University has experienced some challenges in meeting the needs of students entering the University from under-resourced high schools. Many of these high schools have not prepared their students thoroughly for the intense rigor of the curriculum in the fields of science, engineering and mathematics. While the students who are accepted into the College of Engineering possess the intellectual ability and character to succeed at the University, they can be underprepared in math and science and as a result struggle in their first-year courses. Students who are first generation college students often lack academic capital as well ${ }^{3}$. They do not come to campus with the same knowledge base about navigating the college environment as students who have family members with college degrees ${ }^{4}$. The ESA program was developed in order to help promote the success of these students in the College of Engineering.

The ESA was implemented in 2010. In two and a half years, the program has served 44 students, 27 men and 17 women, 20 of whom were Hispanic, 11 were Black, 6 were Asian or Pacific Islander, 3 multiracial, 3 Caucasian, and 1 unknown. Students are invited to join ESA prior to arriving on campus. Indicators that are used to select participants are SAT scores, high school coursework, and underrepresented status in engineering. Students who accept the invitation to join the ESA participate in an ongoing program during the academic year that is focused on facilitating their transition to college and improving their fluency in the use of mathematics, communication skills, and study skills. A professional math educator serves as director of the ESA program. The pedagogy of the program is designed to support its ideals as an academic success and empowerment program ${ }^{5}$. The program is tailored to each student and his or her own academic progress.

The ESA's mission is to help its students make the leap from merely surviving to thriving in engineering. Each of the students in the program meets academic standards indicating that they can succeed in the College of Engineering programs. Before the ESA was instituted, students of similar demographics have frequently graduated with low GPAs or transferred to the College of Arts and Sciences at much higher rates than desired ${ }^{5}$. The ESA strives to retain its students in engineering while maintaining a competitive GPA. To do this, the ESA focuses its programming along three areas: 1) building academic self-efficacy; 2) creating a sense of belonging at the university, in the college, and in the profession; and 3) finding and maintaining balance among the students' academic life, self care, and extracurricular activities. 


\section{Backstage Bucknell}

Historically, in the entry level physics and calculus courses taken by all engineering majors in the first semester, students in the ESA would struggle to earn passing grades on the first exams, which commonly occur during the fourth week of classes. Beginning the ESA at the start of the semester did not allow sufficient time to assist students in establishing good study skills and relationships with faculty in time for the first exam, thus jeopardizing future success in these courses. Traditional summer bridge programs that coincide with summer academic terms and center around earning academic credits come with a high opportunity cost for the students, involving a sacrifice of summer income and time with friends and family, not to mention the high cost of multiple trips to the institution in one summer (often by flying across the country). Working within the budget constraints of a \$25,000 gift to launch the program, as well as the financial and time constraints of students of the ESA, Backstage Bucknell was developed as a six-day residential, pre-orientation program centered around networking and building one’s support system rather than earning academic credits. The initial cohort of participants consisted of 14 students. Backstage Bucknell was themed around a theatrical production where the students were the "stars" of the show. They met and developed relationships with other "cast" and "crew" members during the program. The programming highlighted the importance of the interrelationships between individuals and the session topics to creating a successful “production” (academic year).

Backstage Bucknell was built around the same three goals as the ESA: 1) academic self-efficacy, 2) sense of community and belonging, and 3) maintaining balance. The students arrived prior to the official university orientation to participate in activities geared toward these three areas. At the end of Backstage Bucknell, the students immediately transitioned into the official campuswide first-year orientation. They then also became a part of the ESA's class of 2016.

The goal of building academic success provided the primary context through which all three goals were addressed. Backstage Bucknell students participated in activities related to academic success in calculus, physics, and writing on five of the six days. During these sessions, faculty from the relevant academic departments led review sessions, discussions, and activities addressing study skills, group work, seeking help with material, and how to keep up with work and assignments. Students were also assigned homework that they were expected to complete by the next meeting. Particular times during the day were set aside as recommended homework times, and at each of these times a classroom was reserved for the students to use for group study if they so desired. Students were encouraged to practice and begin to establish good habits in anticipation of the semester. Additional academic sessions on time management tools and proactively using university resources, including those provided by the ESA, were also a part of the academic programming. 
The Backstage Bucknell theme of a behind-the-scenes theatrical production played directly into the second focus area of building a sense of community and belonging. In addition to building relationships with faculty during the academic sessions, participants had opportunities for networking with faculty, staff, and peers throughout campus. Building a sense of belonging began as soon as students arrived on campus. ESA staff and current students greeted Backstage Bucknell students to distribute keys and show them to their dorm rooms for the year. In each room was a welcome bag with not only necessary items such as the schedule for the week, but also the academic tools that ESA students have often avoided purchasing because of their relatively high price tag such as the calculator required for the university's calculus sequence as well as a pad of engineering paper. After a small amount of instruction on the calculator during the week, Backstage Bucknell students began the semester with academic tools on par with their peer group.

Throughout the week, building one's personal and campus network was continually emphasized. Three focused events gave students the opportunity to network with a leader in the profession, with high-level University administration, and with professors and staff with whom they will be interacting over the next several years. Both students and their families attended a welcome dinner on the arrival day. The Dean and Associate Dean of Engineering as well as George Pierson the co-chair of the ESA's Advisory Committee and President and CEO of Parsons Brinckerhoff welcomed the students and their families to the campus and spent time getting to know each student. Later in the week, the president of the university invited the students to join him for lunch. As a first generation college student himself, the president was able to talk with the students about the challenges of the transition to college and to impart advice on how to make the most of their first semester. The students also attended sessions to learn about university resources that will be useful to them such as Psychological Services, the library and Multicultural Student Services that are not covered in detail during the university-wide orientation.

To encourage students to further expand their network, and to allow them to investigate some of their own interests on campus, the students were assigned a week-long activity called "Build Your Network.” The task was to have conversations with any member of the university community around campus. Given that this would be stretching some students far out of their comfort zones, an incentive was provided in the form of gift cards to the University Bookstore as prizes for the students who met the greatest number of people. Students were provided with log sheets where they were to record the name, title and position of the person they had met as well as a few notes on what they learned from the conversation. The students would then request the signature of the individual to complete the entry on the log sheet. Several of the students thoroughly enjoyed the activity and excitedly looked forward to the time available to pursue these new relationships. Interestingly, the students found it awkward to ask the individuals for 
their signatures because they didn't want the person thinking that's the only reason they had approached him or her for a conversation.

The busy Backstage Bucknell schedule deliberately modeled the need to use tools for creating work/life balance during the academic year. Frequent points of dialog and reflection became opportunities to contemplate the need to proactively balance the activities they were experiencing, and several students independently expressed a realization that they would be responsible for creating their own schedules in a few short days. Time was set aside during the day for doing homework as well as time for going to the gym or participating in other wellness activities. Evening social events varied in structure, from a movie to an evening spent on the quad with the new first-year international students in outdoor activities. Small games were interjected during the day for natural energy boosts. Students were required to show up for meals, especially breakfast, to stress the importance of healthy eating habits and self care.

\section{Assessment and Results}

Two surveys were administered to the 14 Backstage Bucknell participants to assess the impact of the program. The first survey was administered immediately at the end of the Backstage Bucknell before orientation and the second was administered five weeks after the beginning of classes after the first round of exams had been given in both physics and math.

At the end of the Backstage Bucknell, the students' responses to the survey showed that they greatly valued the preparation sessions in math and physics and suggested that more time be devoted to these topics in the future. The student feedback, as well as faculty and staff reflection, also suggested that the six-day program was simply not long enough to include meaningful instruction and practice with writing. These elements will likely be modified in the future. It was also evident that beyond the discussion of academic skills, the disciplinary focus empowered the faculty participants to interact with the students within the familiar boundaries of their academic expertise initiating positive professor-student interactions. Both surveys demonstrated that one of the key benefits of the Backstage Bucknell was the time invested in the students' gaining familiarity and comfort in interacting with the faculty.

Time management skills proved to be among the most valuable lessons learned by the Backstage Bucknell students. The students participated in a session with the Associate Dean of the College regarding time management and introducing them to the university's electronic calendaring system. The students' upcoming fall semester course schedules were used to provide concrete context for the discussion. Of all the academic and enrichment sessions, this session was ranked among the most useful by the students, with eleven of thirteen students rating it as something to "Do it again and don’t change it” and the other two both rating it as "Do it again.” The intentionally busy Backstage Bucknell schedule also helped the students internalize valuable 
lessons about the difficulty of finding work/life balance in college. When asked about the schedule in the impact surveys several students indicated lessons learned about balancing academics, social life, and self such as:

.... it was difficult being expected to do homework assignments when the activities ended at about 10 in the evening.

Hour breaks were nice but flew by so quickly. Schedule was very packed and busy, good practice.... Food inclusion was a nice habit to adjust to.

The long day with math, [Library and IT], writing and another session of math (or physics) was tightly scheduled and tiring. I see it beneficial for students whose schedules could have a day(s) like it but the breaks could be a bit longer for these days.

When asked about the program leadership, students were enthusiastic. Some would have liked to see more engineering professors involved in a leadership role in the program as well as additional [ESA] students, but others responded that "the group dynamic flowed really well with just two adults and two college [ESA] students.” When asked about the length of the Backstage Bucknell, 9 out of 14 students responded that it was "just right" with two each responding that it was "too long” or "too short." (No one responded that it was "way too long” or "way too short.")

When the participants were asked after the beginning of the semester whether they felt better prepared academically as a result of the Backstage Bucknell program, $75 \%$ responded that the Backstage Bucknell had helped them with their first semester. The students reported that the time management and calendaring session was crucial, and they clearly felt advantaged by the early introductions to the campus facilities and support offices. All participants felt strongly that they had developed a supportive cohort of students and $92 \%$ of participants would recommend the Backstage Bucknell program to other students. The student responses to their perception of having developed a supportive cohort of peers increased on the mid semester survey administration from the initial survey administration. It seems the peer connections made during the Backstage Bucknell program continued and strengthened as the semester progressed.

There are indicators that the Backstage Bucknell program increased the academic performance of the participants in their first semester physics course as seen in Table 1 which compares exam scores for the Backstage Bucknell ESA 2016 participants and the previous year's ESA 2015 cohort. All first-year engineering students are required to take an introductory, calculus-based physics course in which all students are given common exams. In this course there was a significant increase in the scores on the first exam as compared to the whole class average for the Backstage Bucknell ESA 2016 participants as compared to the ESA 2015 class. 
Table 1 Comparison of Exam Scores in Physics for Backstage Bucknell Participants vs. ESA non-Participants

\begin{tabular}{|c|c|c|c|c|}
\hline $\begin{array}{c}\text { Physics } \\
\text { Exam }\end{array}$ & $\begin{array}{c}\text { Exam Average and } \\
\text { Standard Deviation } \\
\text { (STD), all students in } \\
\text { the class, fall 2011 }\end{array}$ & $\begin{array}{c}\text { ESA 2015 Exam } \\
\text { Average, no } \\
\text { Backstage } \\
\text { Bucknell }\end{array}$ & $\begin{array}{c}\text { Exam Average and } \\
\text { Standard Deviation } \\
\text { (STD), all students in } \\
\text { the class, fall 2012 }\end{array}$ & $\begin{array}{c}\text { ESA 2016, with } \\
\text { Backstage } \\
\text { Bucknell }\end{array}$ \\
\hline Exam 1 & $76 \%$, STD 15 & $61 \%$ & $69 \%$, STD 16 & $65 \%$ \\
\hline Exam 2 & $81 \%$, STD 14 & $67 \%$ & $78 \%$, STD 12 & $71 \%$ \\
\hline Exam 3 & $76 \%$, STD 15 & $68 \%$ & $80 \%$, STD 14 & $76 \%$ \\
\hline
\end{tabular}

In the fall of 2011, the average of the exam scores on Exam 1 and 2 for the ESA 2015 students was a full standard deviation below the class average. The ESA 2015 students' exam average on the third exam improved in fall 2011 as two students by that point in the semester dropped the course and did not take Exam 3. In the fall of 2012, the average for the Backstage Bucknell ESA 2016 students for the first exam was within one fourth of a standard deviation from the course average. This increase in performance continued throughout the remainder of the physics exams with the average of the exam scores for each exam for the Backstage Bucknell ESA 2016 participants being within one half of one standard deviation away from the class average. None of the Backstage Bucknell ESA 2016 students withdrew from or failed the physics course in the fall of 2012.

In math the Backstage Bucknell ESA 2016 students performed similarly to the students in the ESA 2015 cohort. All levels of calculus at the university are taught in multiple sections with multiple faculty. The courses are specific to the faculty member and there are no common exams as with the introductory physics class. The average final course grade earned by both groups in their first math course at the university was a B-. The final course grades of the Backstage Bucknell ESA 2016 participants had 2 out of 14 students earning less than a $C$ for their final course grade. In the ESA 2015 group, 3 out of 13 students received a final course grade less than C. It is worth noting that the lowest grade earned in any level of calculus by the students in the Backstage Bucknell ESA 2016 or the fall ESA 2015 class was a C-. Since the inception of the ESA, the regular academic year programming for the ESA program has focused on increasing academic success in mathematics. It is possible that this strong math emphasis, already present before the addition of the Backstage Bucknell component, produces the greatest gains in math completion ${ }^{5}$. This is supported by the average final course grade of B- for both groups.

The average of the cumulative GPAs for the Backstage Bucknell ESA 2016 participants after their first college semester was a 2.80. The average for the ESA 2015 group was a 2.70. Overall the academic performance of the Backstage Bucknell participants increased when compared to the previous group. Given that the student selection process and other programming for the ESA 
students has been the same this academic year as in the past, it seems that these increases in performance could be attributed to the Backstage Bucknell.

\section{Conclusions}

An intensive, week-long, residential pre-orientation program named Backstage Bucknell was designed and implemented to improve the first-semester academic performance of students in the Engineering Success Alliance Program. This six-day pre-orientation program was focused on networking and building one's support system. Academic performance in the required firstsemester introductory physics course increased along with the cumulative first-semester GPAs of the students in the Backstage Bucknell as compared to first-year ESA participants in the previous year. Backstage Bucknell participants indicated that the following activities positively influenced their first semester experience:

1) Extensive opportunities to interact with peers, faculty, university administrators and campus community members helped to develop academic self-efficacy and a sense of belonging within the university. Students noted increases in confidence due to their early introduction to faculty and campus resources. This model was also effective in developing a lasting supportive cohort of peers among the Backstage Bucknell participants.

2) Students greatly valued activities such as academic preparedness sessions in mathematics and physics as well as time management workshops that were geared toward helping them develop useful and necessary skills for success in their first semester. Meaningful instruction in writing was difficult to execute in this compressed time frame.

3) Nearly all participants felt that the program was of an appropriate length to achieve the goals of the Backstage Bucknell and would recommend the program in this format to another student. Gains in the three focus areas of the program were possible despite the compressed time frame.

Even in its first year, the Backstage Bucknell program was a resounding success, both on measures of student self-report and improvement in physics final course grades and overall academic performance through the semester. Students frequently used words such as "invaluable” and "fantastic" in discussing the program. The Backstage Bucknell is intended to become a permanent part of the ESA with continual improvements to the program anticipated to yield even more powerful results. 


\section{References}

1) National Research Council, (2007), Rising Above the Gathering Storm: Energizing and Employing America for a Brighter Economic Future, Washington, DC: The National Academies Press.

2) National Research Council, (2010), Rising Above the Gathering Storm, Revisited: Rapidly Approaching Category 5, Washington, DC: The National Academies Press.

3) St.John, E.P., S. Hu, and A.S. Fisher., (2010), Breaking Through the Access Barrier: How Academic Capital Formation Can Improve Policy in Higher Education. New York, NY: Routledge

4) Elam, C., Stratton, t., and Gibson, D.D., (2007), "Welcoming a New Generation to College: The Millennial Students”, Journal of College Admission, (195), 20-25.

5) Marosi, K. and Steinhurst, Barbra (2012), "Increasing the Retention of Under-Represented Students in Engineering Through Connections with An Industry Advisory Committee,” American Society of Engineering Education annual conference proceeding, San Antonio, TX. 